\title{
History, Expectations, and Public Policy: Economic Development in Eastern Germany
}

\author{
Andreas Schäfer \\ Thomas Steger
}

\author{
CESIFO WORKING PAPER NO. 3184 \\ CATEgory 6: Fiscal Policy, Macroeconomics AND GROWTH \\ SEPTEMBER 2010
}

An electronic version of the paper may be downloaded

- from the SSRN website:

- from the RePEc website:

- from the CESifo website:

www.SSRN.com

Www.RePEc.org

www.CESifo-group.org/wp 


\title{
History, Expectations, and Public Policy: Economic Development in Eastern Germany
}

\begin{abstract}
Motivated by the process of economic development in Eastern Germany since the German reunification we set up a dynamic macroeconomic model of a small open economy where both capital and labor are mobile and there are increasing returns to scale at the aggregate level. The model features multiple equilibria as well as (local and global) indeterminacy. Expectations matter for resulting equilibrium dynamics, implying that economic confidence may be crucial for the process of economic development. Despite its simplicity, the model can replicate major empirical facts and bears a number of non-trivial implications.
\end{abstract}

JEL-Code: E60, H20, O40.

Keywords: increasing returns to scale, capital mobility, migration, multiple equilibria, indeterminacy, history vs. expectations, economic policy.

\author{
Andreas Schäfer \\ University of Leipzig \\ Institute for Theoretical Economics \\ Grimmaische Strasse 12 \\ 04019 Leipzig \\ Germany \\ schaefer@wifa.uni-leipzig.de
}

\author{
Thomas Steger \\ University of Leipzig \\ Institute for Theoretical Economics \\ Grimmaische Strasse 12 \\ 04019 Leipzig \\ Germany \\ steger@wifa.uni-leipzig.de
}

This version: September 14, 2010

We are grateful to Max Albert, Volker Grossmann, Juergen Meckl, and Harald Uhlig for valuable and constructive comments. 


\section{Introduction}

The German reunification in 1991 represents a drastic example of an economy that was subject to a comprehensive integration shock. After 1991 a whole economy with hitherto highly restricted labor and capital mobility, namely East Germany, became integrated into a nearly frictionless world labor and capital market. In this paper we address the question about the determinants of macroeconomic development in response to such far-ranging changes in institutional settings. We argue that an empirically plausible macroeconomic model should exhibit multiple long run equilibria. The major question then concerns the mechanisms that may lead the economy either to the good or to the bad long run equilibrium. The literature, discussed below, has stressed "history" (initial conditions) and "expectations" (confidence, moods, sentiment) as potential equilibrium selection mechanisms. A better understanding of the process of macroeconomic development in small open economies requires that both the relative importance as well as the possible interaction between these mechanisms need to be clarified. In addition, it is unclear how public policy interacts with these mechanisms in the process of equilibrium selection. We take the prominent example of Eastern Germany as an opportunity to study an economy where factors of production are unexpectedly given the possibility of moving out of or into the domestic market economy.

The neoclassical textbook model does not appear helpful when trying to better understand this process. Suppose that output $Y$ is produced under constant returns to scale according to $Y=K^{\alpha} L^{1-\alpha}$ and that both capital $K$ and labor $L$ have an outside option, denoted as $\bar{r}$ and $\bar{w}$. It can be easily verified that the equilibrium capital intensity and per capita output are then given by $\tilde{k}=\frac{\alpha \bar{w}}{(1-\alpha) \bar{r}}$ and $\tilde{y}=\tilde{k}^{\alpha}$ (the size of the economy in terms of, say, $L$ is indeterminate). Provided that all economies face the same outside options $(\bar{r}$ and $\bar{w})$ and have access to the same technology, one should observe convergence in capital intensities and in the level of per capita incomes. However, this implication is at odds with real-world experience. For instance, Uhlig (2006, p. 383) has pointed to the observation of "limited convergence" between Eastern and Western Germany. Moreover, if we think of a national economy as being composed of a set of 
regional economies, and assume that every region satisfies the conditions mentioned above, then we should clearly expect convergence in regional per capita incomes. However, also this implication appears to be at odds with the data, at least for Eastern Germany (see Section 2).

We employ a straightforward modification of the textbook model sketched above to better understand the process of macroeconomic development in Eastern Germany. Two modifications are undertaken. First, we assume that factor relocation is subject to mobility costs. This assumption introduces the dynamic dimension and implies that agents need to form expectations about the future. Second, there are increasing returns to scale (IRS) at the aggregate level due to productive government expenditures. As a consequence, there are multiple equilibria (ME) as well as (local and global) indeterminacy implying that expectations matter for resulting equilibrium dynamics. More specifically, expectations may be crucial, first, for the steady state the economy approaches in the long run and, second, for the equilibrium trajectory which leads the economy to the (inferior or superior) steady state.

The small scale model employed in this paper is in line with major stylized facts, described in Section 2, and delivers a number of non-trivial implications. Among these are the following: (i) the success of macroeconomic development is determined by history and expectations; (ii) the relative importance of expectations as major determinant of macroeconomic success depends on public policy in a systematic fashion; and (iii) the set of admissible, i.e. fundamentally warranted, expectations depends on initial conditions and on public policy.

Two strands of related literature should be mentioned. First, there are by now a number of contributions which focus on the process of macroeconomic development in Eastern Germany. For instance, Funke and Strulik (2000) and Burda (2006) have investigated the pattern of East-West convergence employing dynamic macroeconomic models. Snower and Merkl (2006) and Uhlig (2006) have studied the sources and consequences of the substantial and persistent increase in unemployment figures using labor market models. Second, there is a large number of contributions dealing with IRS and ME in real macroeconomic models (e.g. Murphy et al., 1989; Benhabib and 
Farmer, 1994). It is well known that IRS may lead to ME. An important question, then, is how the process of equilibrium selection works. Most models imply that initial conditions are crucial (Deissenberg et al., 2001). Krugman (1991) has demonstrated that it is, in principle, both history and expectations that matter.

The paper contributes to a better understanding of the process of macroeconomic development in small open economies in general and, more specifically, in Eastern Germany since 1991. It demonstrates that both history and expectations matter. In addition, it is shown that gradual changes in public policy measures may lead to drastic changes in economic outcomes. Moreover, our paper contributes also to the literature which discusses the mechanisms of equilibrium selection in models with ME by demonstrating that the relative importance of expectations depends on public policy in a systematic fashion.

The paper is structured as follows. Sections 2 describes major stylized facts of macroeconomic development in Eastern Germany since 1991. Section 3 sets up the basic model, describes the resulting dynamic system and the implied steady state solutions. Section 4 is devoted to the discussion of stability, equilibrium dynamics and global indeterminacy. Section 5 illustrates the model implications by conducting numerical evaluations. Section 6 summarizes and concludes.

\section{Some stylized facts}

The process of real macroeconomic development in Eastern Germany since 1991 may be sketched by the following list of stylized facts: ${ }^{1}$

1. Real GDP per capita grew by an average annual rate of 3.6 percent between 1991 and 2007.

2. The standard deviation of real GDP per capita across Eastern German regions increased between 1992 and 2006 by roughly 80 percent (country subdivisions according to NUTS

\footnotetext{
${ }^{1}$ The data for stylized facts 1 . to 3 . are taken, respectively, from: 1 . Arbeitskreis "Volkswirtschaftliche Gesamtrechnungen der Laender" (2008(a)); 2. Arbeitskreis "Volkswirtschaftliche Gesamtrechnungen der Laender" (2008(b)), 3. Statistisches Bundesamt, Genesis database (2008).
} 
2, "Regierungsbezirke") and by 114 percent (country subdivisions according to NUTS 3, "Kreise"). ${ }^{2}$

3. At the aggregate level there has been substantial emigration. Between 2000 and 2006 about 70,000 people (0.5 percent of the population) emigrated from Eastern Germany per annum (Burda, 2006, p. 368). ${ }^{3}$ However, there are important regional differences. Some regions shrank substantially and, at the same time, there are regions which attracted people to a substantial extent.

4. At the aggregate level there has been a substantial inflow of private capital. From 1991 to 2004 capital inflows amounted to 80 to 90 billion EUR, or about 20 percent of GDP, each year (Burda, 2006, p. 368).

5. Between 1991 and 2004 Eastern Germany has received massive fiscal transfers of about 80 billion EUR per year ( 4 percent of Germany's GDP). About 50 percent constitute social assistance (Snower and Merkl, 2006, p. 375).

The observation of regional divergence of per capita incomes (stylized fact \#2) provides important evidence with regard to the underlying macroeconomic structure. The divergence pattern among Eastern German regions is therefore considered more deeply. Figure 1 shows the time path of the standard deviation of real GDP per capita between 1991 and 2006 for country subdivisions NUTS 2 ("Regierungsbezirke") and for country subdivisions NUTS 3 ("Kreise"). Both graphs clearly indicate regional divergence. Moreover, Figure 2 shows the kernel density estimation (essentially a smoothed histogram) for the regional distribution of GDP per capita (country

\footnotetext{
${ }^{2}$ Divergence at the level of Eastern German "Laender" (NUTS 1) is less pronounced. The standard deviation increased between 1991 and 2007 by roughly $29 \%$.

${ }^{3}$ Moreover, the unemployment rate increased from 10 percent in 1991 to almost 20 percent in 2004 (Snower, Merkl, 2006, p. 375).
} 
subdivisions NUTS 3) in 1996 and 2006. ${ }^{4}$ These plots confirm regional divergence of per capita incomes. The regional income distribution in 1996 appears unimodal, whereas in 2006 it appears bimodal. The upper tale became thicker, i.e. there are regions clustering in the upper range of regional income distribution. ${ }^{5}$ Vollmer et al. (2010) decompose the (entire) German distribution of annual GDP per employee into two components using a two-component normal mixture model for the years 1992 until 2006. This allows them to identify those districts (NUTS 3) that moved from the first to the second component. Subsequently, a standard cross-sectional growth regression is extended to include a mover dummy, which is highly significant. The growth rate of a mover district is about one percentage point higher than the growth rate of non-mover district which had the same GDP per worker in 1992. Vollmer et al. (2010, p. 10) conclude "...that districts in the East converge to two different steady states regardless of their initial GDP" and state "...we can see two convergence clubs in the East that start to separate between 1999 and 2001".

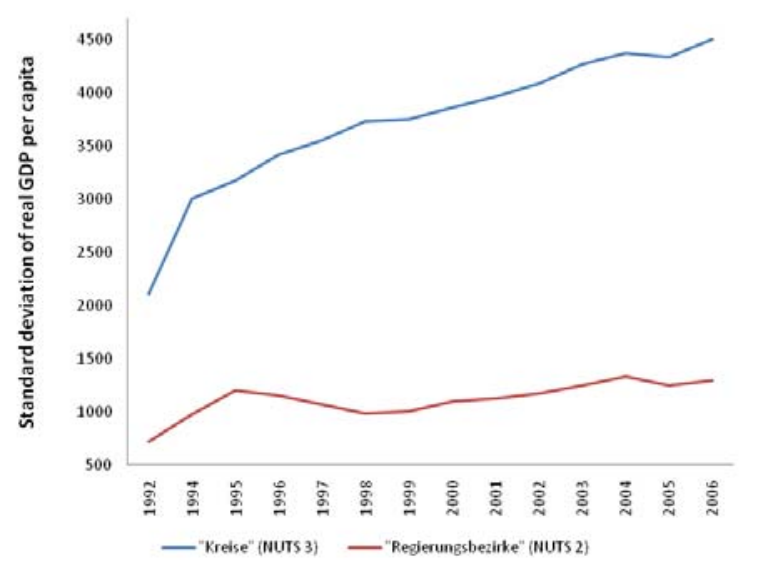

Figure 1: Divergence among East German Regions.

\footnotetext{
${ }^{4}$ A complete data set for the 102 East German "Kreise" is available for the first time in 1996. The results for 1994 and 1995 are qualitatively identical (for 1993 no data is provided). For 1992 the data set comprises only 82 "Kreise". The kernel density graph is produced using EViews. As kernel density weighting function the Epanechnikov kernel (default option) is used and the bandwidth parameter (controlling the smoothness of the graph) is data-based.

${ }^{5}$ The following "Kreise" have more than 45 perecnt of average Eastern GDP per capita in 2006: Dresden, Erfurt, Jena, Neubrandenburg, Potsdam, Schwerin, Wismar, Zwickau.
} 


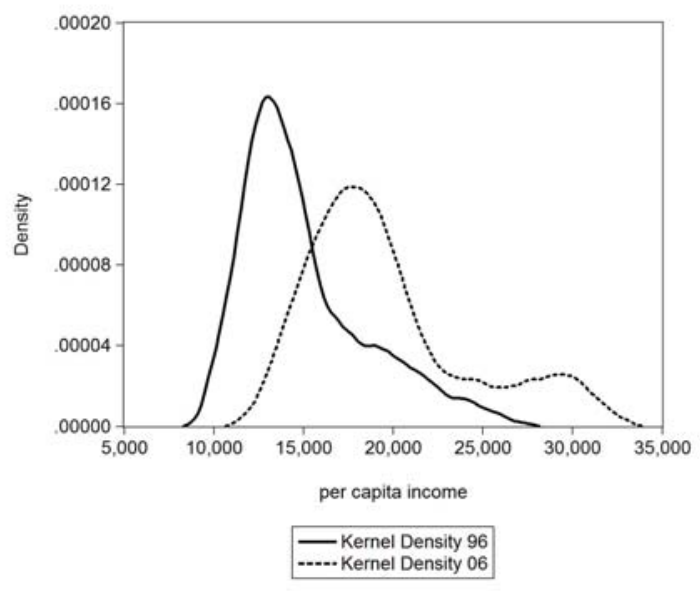

Figure 2: The emergence of twin peaks.

It should be observed that this divergence pattern is in stark contrast to the basic neoclassical model. This conclusion is reinforced by noting that the degree of factor mobility appears to be quite high. Eastern Germany has unrestricted access to the international capital market and major migration costs associated with cultural and lingual differences do not apply (Hunt, 2006). Moreover, there are substantial productive government expenditures, funded by the central government, which aim at a "harmonization of living conditions" (as prescribed by the German constitution) by uniformly distributed public infrastructure investment. ${ }^{6}$

\section{The model}

We consider a dynamic one-sector model of a small open economy, which comprises a number of $n$ regions. Every region is identical except for the initial amount of labor and capital allocated to the region's domestic market sector and the degree of initial optimism or pessimism. For simplicity regions do not interact. Both labor and capital have an outside option. Moving input factors out

\footnotetext{
${ }^{6}$ The prescription of "harmonization of living conditions" is codified in Art. 72, § 106(3) and Art. 20 of the German Constitution ("Grundgesetz").
} 
of or into the domestic market sector is associated with mobility costs. The model features IRS at the aggregate level due to productive government expenditures à la Barro (1990). Technically, this model can be viewed as a two-dimensional extension of the Krugman (1991) model.

\subsection{Production technology and factor prices}

Regional output $Y_{i}$ is produced according to a standard Cobb-Douglas technology, as given by

$$
Y_{i}=G_{i}^{\beta} K_{i}^{\alpha} L_{i}^{1-\alpha}
$$

where $G_{i}$ denotes regional productive government expenditures (e.g., regional infrastructure investment, commercial zone development investment), $K_{i}$ is capital employed in region $i, L_{i}$ is the amount of labor employed in region $i$, where $i \in\{1, \ldots, n\}$ indexes the regions, and $0<\beta, \alpha<1$. We assume that regional productive government expenditures are proportional to regional tax receipts, i.e.

$$
G_{i}=q \tau Y_{i}
$$

where $0 \leq \tau \leq 1$ denotes the unique tax rate levied on capital and labor income and $q>0$ is the share of local tax receipts which is used to finance productive government expenditures. We do not impose a balanced budget $(q=1)$ for two reasons: First, there are other uses of tax receipts which are not modeled here (e.g., social transfers) and, second, regional productive government expenditures are typically matched by grants provided by the central government (hence $q$ might be even larger than unity). The crucial assumption here is that there are (regional) productive government expenditures, labeled $G_{i}$, which vary positively with regional tax receipts. ${ }^{7}$ This might capture productive government expenditures financed exclusively by regional authorities or productive government expenditures co-financed by the central government through matching

\footnotetext{
${ }^{7}$ Regional tax receipts in Germany are primarily composed of a share of the personal income tax, a share of the value added tax, and the corporate income tax.
} 
grants. $^{8}$

Using $G_{i}=q \tau Y_{i}$ the reduced form technology reads

$$
Y_{i}=(q \tau)^{\frac{\beta}{1-\beta}} K_{i}^{\frac{\alpha}{1-\beta}} L_{i}^{\frac{1-\alpha}{1-\beta}}
$$

Notice that this model features IRS, since $\frac{1}{1-\beta}>1$, in capital and labor at the aggregate level. ${ }^{9}$ Forming the partial derivative of equ. (1) with respect to $L_{i}$ and $K_{i}$, holding $G_{i}$ fixed, and subsequently using $G_{i}=q \tau Y_{i}$ gives the competitive factor prices

$$
\begin{gathered}
w_{i}=\frac{\partial Y_{i}}{\partial L_{i}}=(1-\alpha)(q \tau)^{\frac{\beta}{1-\beta}} K_{i}^{\frac{\alpha}{1-\beta}} L_{i}^{\frac{\beta-\alpha}{1-\beta}}, \\
r_{i}=\frac{\partial Y_{i}}{\partial K_{i}}=\alpha(q \tau)^{\frac{\beta}{1-\beta}} K_{i}^{\frac{\alpha-1+\beta}{1-\beta}} L_{i}^{\frac{1-\alpha}{1-\beta}},
\end{gathered}
$$

where $w_{i}$ denotes the wage rate and $r_{i}$ the rate of return to capital in region $i$. Under (aggregate) IRS, the level of factor prices and, hence, the level of per capita income is crucially determined by the amount of labor and capital allocated to the domestic market sector. Therefore, we turn to the allocation decisions of workers and capital owners at next.

\subsection{Workers}

There are $L_{i}(0)=L_{i o}$ identical workers initially in region $i$, who live forever (to simplify notation, the region index is suppressed in what follows). Each worker supplies one unit of time per time period, independent of the wage rate, to the labor market. East German workers have the possibility of moving to Western Germany. Migration decisions are modelled according to Braun

\footnotetext{
${ }^{8}$ Public policy instruments which are designed as matching grants comprise sponsorships within the framework of "Gemeinschaftsaufgabe" and "Europäische Strukturförderung" (Bundesministerium für Verkehr, Bau und Stadtentwicklung, 2006)

${ }^{9}$ The mechanism that gives rise to (aggregate) IRS is productive government expenditures. The basic results described below do not, however, depend on this specific mechanism.
} 
(1993). ${ }^{10}$ The benefit of moving from Eastern to Western Germany at $t=0$ is reflected by

$$
\lambda_{L}^{W}(0)=\int_{0}^{\infty}[\bar{w}-(1-\tau) w] e^{-\rho t} d t
$$

where $\rho>0$ denotes the time preference rate, $w$ is the competitive wage rate in Eastern Germany, $0<\tau<1$ is a linear labor income tax, and $\bar{w}$ is the wage rate (net of taxes) that can be earned in Western Germany. Notice that $\lambda_{L}^{W}(0)$ gives the present value of the difference between earnings in the outside option and in the domestic market sector. Since the competitive wage rate $w$ depends on the amount of labor and capital employed in the domestic market sector, $\lambda_{L}^{W}(0)$ captures expectations about the future economic development.

The cost per migrant is given by

$$
m c=\frac{1}{\gamma_{L}} \dot{L}_{E W}
$$

where $\dot{L}_{E W} \geq 0$ denotes the flow of migrants from Eastern to Western Germany per period of time. The parameter $\gamma_{L}>0$ is an inverse measure of the importance of moving cost. According to equ. (7) migration cost are assumed to increase with the number of migrants due to congestion (cf. Braun, 1993, p. 24). ${ }^{11}$ Notice that the individual moving decision is a binary decision. Migrants leave the economy if the benefit of migration, reflected by $\lambda_{L}^{W}$, exceeds the migration cost given by $m c$. In competitive equilibrium the benefit of migration must equal the cost of migration, i.e. $\lambda_{L}^{W}=\frac{1}{\gamma_{L}} \dot{L}_{E W}$ (cf. Braun, 1993, p. 25). Moreover, if the benefit of leaving Eastern Germany is zero, $\lambda_{L}^{W}=0$, no one will want to emigrate, i.e. $\dot{L}_{E W}=0$. Similarly, provided that $\lambda_{L}^{W}<0$, one gets $\dot{L}_{E W}=0$. In summary, East-West migration may be described as follows

\footnotetext{
${ }^{10}$ The Braun (1993) model of migration and growth represents a dynamic, representative-agent model (see also Barro and Sala-i-Martin, 2004, Chapter 9.1.3).

${ }^{11}$ The key property is that the cost of moving for the marginal mover rises with the number of movers. This relation would also hold if there were heterogeneity with respect to moving costs. The persons with lower costs would move sooner, and the cost of moving would therefore rise at the margin with the number of movers (Barro and Sala-i-Martin, 2004, p. 401).
} 


$$
\dot{L}_{E W}=\left\{\begin{array}{ccc}
\gamma_{L} \lambda_{L}^{W} & \text { for } \quad \lambda_{L}^{W}>0 \\
0 & \text { for } \quad \lambda_{L}^{W}=0 \\
0 & \text { for } \quad \lambda_{L}^{W}<0
\end{array}\right.
$$

Consider at next the typical West German inhabitant. Let $\lambda_{L}^{E}(0)=\int_{0}^{\infty}[(1-\tau) w-\bar{w}] e^{-\rho t} d t$ denote the value of being in Eastern rather than being in Western Germany; also notice that $\lambda_{L}^{W}=-\lambda_{L}^{E}$. The cost per migrant is again given by $m c=\frac{1}{\gamma_{L}} \dot{L}_{W E}$, where $\dot{L}_{W E} \geq 0$ denotes the flow of migrants from Western to Eastern Germany per period of time. Applying an analogous reasoning as before yields

$$
\dot{L}_{W E}=\left\{\begin{array}{ccc}
\gamma_{L} \lambda_{L}^{E} & \text { for } & \lambda_{L}^{E}>0 \\
0 & \text { for } & \lambda_{L}^{E}=0 \\
0 & \text { for } & \lambda_{L}^{E}<0
\end{array} .\right.
$$

The number of workers in the Eastern German region, denoted as $L$, changes according to

$$
\dot{L}=\dot{L}_{W E}-\dot{L}_{E W}
$$

We now draw the following case distinction

1. Assume $\lambda_{L}^{W}>0$ (implying $\lambda_{L}^{E}<0$ ). Noting (8), (9), (10) this gives $\dot{L}=\underbrace{\dot{L}_{W E}}_{=0}-\dot{L}_{E W}=$ $-\gamma_{L} \lambda_{L}^{W}<0$.

2. Assume $\lambda_{L}^{W}=0$ (implying $\lambda_{L}^{E}=0$ ). Noting (8), (9), (10) this gives $\dot{L}=\underbrace{\dot{L}_{W E}}_{=0}-\underbrace{\dot{L}_{E W}}_{=0}=0$.

3. Assume $\lambda_{L}^{W}<0$ (implying $\lambda_{L}^{E}>0$ ). Noting (8), (9), (10) this gives $\dot{L}=\dot{L}_{W E}-\underbrace{\dot{L}_{E W}}_{=0}=$ $-\gamma_{L} \lambda_{L}^{W}>0$

In summary, the equation of motion for $L$, recalling $\lambda_{L}^{W}=-\lambda_{L}^{E}$, may be expressed as follows

$$
\dot{L}=\gamma_{L} \lambda_{L}^{E} \lesseqgtr 0 \text { for } \lambda_{L}^{E} \lesseqgtr 0 .
$$

A clarification may be warranted. Consider Eastern German regions which satisfy $\lambda_{L}^{E}>0$. Does the model imply that the region with the highest wage rate attracts Western German workers first 
and then other regions develop at next? Assuming that there are enough workers outside the economy for a simultaneous development of all regions which experience a favorable economic development, the answer is no.

\subsection{Capital owners}

Every Eastern German region is populated by a continuum of length one of identical capital owners. ${ }^{12}$ Each capitalist is endowed with $\bar{K}_{E}$ units of capital. Capital can be employed in the region's domestic market sector earning a rate of return $r$. Alternatively, capital can be invested abroad to earn the fixed rate of return $\bar{r}>0$. The representative East German capital owner maximizes the present value of an infinite income stream, i.e. solves the following problem

$$
\begin{aligned}
& \max _{\left\{v_{K}^{E}\right\}} \int_{0}^{\infty}[(1-\tau) r K_{E}+\bar{r} \underbrace{\left(\bar{K}_{E}-K_{E}\right)}_{=0 \text { at }}-\frac{1}{2 \gamma_{K}}\left(v_{K}^{E}\right)^{2}] e^{-\rho t} d t \\
& \text { s.t. } \dot{K}_{E}=v_{K}^{E} \\
& K_{E}(0)=\bar{K}_{E}, 0 \leq K_{E} \leq \bar{K}_{E},
\end{aligned}
$$

where $\rho>0$ denotes the time preference rate and $\dot{K}:=d K / d t$. Moving capital from the region's domestic market sector to the outside option, or vice versa, causes (symmetric and convex) capital adjustment costs which reduce current income, as captured by the term " $-\frac{1}{2 \gamma_{K}}\left(v_{K}^{E}\right)^{2}$ ", where $v_{K}^{E}$ denotes a control variable. More precisely, moving one additional unit of capital from, say, Eastern to Western Germany causes relocation costs of $\frac{\dot{K}_{E}}{\gamma_{K}}$, i.e. marginal adjustment costs increase with the flow of capital being transferred. ${ }^{13}$ The parameter $\gamma_{K}>0$ is an inverse measure of the importance

\footnotetext{
${ }^{12}$ To simplify, we assume that capital owners don't move. The location of capital owners is not important since we are interested in the determinants of GDP, not in the determinants of GNP.

${ }^{13}$ There are indeed convex capital reallocation costs at the individual level. This is consistent with the following interpretation. If the individual capital owner transfers financial funds, no cost is incurred. The accumulation of physical capital is, however, associated with convex capital adjustment costs, even at the individual level according to Hayashi (1982).
} 
of adjustment costs. Notice also that, by assumption, the East German capital owner has all his capital $\bar{K}_{E}$ allocated to the East German region initially, i.e. $K_{E}(0)=\bar{K}_{E}$. Thus he can either keep all his capital inside the region's domestic market sector or start investing abroad. An increase in the region's stock of capital then requires foreign capital inflows.

Let $H_{E}:=H_{E}\left(K_{E}, v_{K}^{E}\right)$ denote the associated (current value) Hamiltonian function. The first-order conditions read as follows

$$
\begin{gathered}
\frac{\partial H_{E}}{\partial v_{K}}=-\frac{1}{\gamma_{K}} v_{K}+\lambda_{K}^{E}=0 \Longrightarrow v_{K}=\gamma_{K} \lambda_{K}, \\
\dot{\lambda}_{K}^{E}=\rho \lambda_{K}^{E}-\frac{\partial H_{E}}{\partial K}=\rho \lambda_{K}^{E}-[(1-\tau) r-\bar{r}] .
\end{gathered}
$$

The efficiency condition (12) says that, in equilibrium, marginal moving cost $\frac{v_{K}}{\gamma_{K}}$ must equal the shadow price $\lambda_{K}^{E}$. Equation (13) indicates that $\lambda_{K}^{E}(0)=\int_{0}^{\infty}[(1-\tau) r-\bar{r}] e^{-\rho t} d t$, i.e. $\lambda_{K}^{E}(0)$ gives the present value of the difference between earnings in the domestic market sector and in the outside option. ${ }^{14}$ As before, since the competitive rate of return $r$ depends on the amount of capital and labor employed in the domestic market sector, $\lambda_{K}(0)$ captures expectations about future economic development.

The problem of the typical West German capital owner may be expressed as follows

$$
\begin{aligned}
& \max _{\left\{v_{K}^{W}\right\}} \int_{0}^{\infty}[\bar{r} K_{W}+(1-\tau) r \underbrace{\left(\bar{K}_{W}-K_{W}\right)}_{=0 \text { at } t=0}-\frac{1}{2 \gamma_{K}}\left(v_{K}^{W}\right)^{2}] e^{-\rho t} d t \\
& \text { s.t. } \dot{K}_{W}=v_{K}^{W} \\
& K_{W}(0)=\bar{K}_{W}, 0 \leq K_{W} \leq \bar{K}_{W} .
\end{aligned}
$$

The typical West German capital owner has total wealth $\bar{K}_{W}$, which is completely invested in West Germany (or the rest of the world) initially.

Physical capital invested in the Eastern German region is given by $K=K_{E}+\left(\bar{K}_{W}-K_{W}\right)$,

\footnotetext{
${ }^{14}$ This solution for $\lambda_{K}^{E}(0)$ requires that the boundary condition $\lambda_{K}^{E}(T)=0$ (the so-called "soft landing condition") holds, where $T$ denotes the point in time where the economy hits a boundary (see Section 3.4).
} 
implying that the rate of change in physical capital per period of time may be expressed as

$$
\dot{K}=\dot{K}_{E}-\dot{K}_{W}
$$

Let $\lambda_{K}^{W}(0)$ denote the shadow value placed on capital invested in Western Germany, i.e. $\lambda_{K}^{W}(0)=\int_{0}^{\infty}[\bar{r}-(1-\tau) r] e^{-\rho t} d t$. It can then be readily shown that the following relations must hold in equilibrium (from $\frac{\partial H_{K}}{\partial v_{K}^{E}}=0, K_{E} \leq \bar{K}_{E}$ and $\frac{\partial H_{K}}{\partial v_{K}^{W}}=0, K_{W} \leq \bar{K}_{W}$ )

$$
\begin{gathered}
\dot{K}_{E}=\left\{\begin{array}{ccc}
\gamma_{K} \lambda_{K}^{E} & \text { for } \quad \lambda_{K}^{E}<0 \\
0 & \text { for } \quad \lambda_{K}^{E}=0 \\
0 & \text { for } & \lambda_{K}^{E}>0
\end{array}\right. \\
\dot{K}_{W}=\left\{\begin{array}{ccc}
\gamma_{K} \lambda_{K}^{W} & \text { for } & \lambda_{K}^{W}<0 \\
0 & \text { for } & \lambda_{K}^{W}=0 \\
0 & \text { for } & \lambda_{K}^{W}>0
\end{array}\right.
\end{gathered}
$$

Notice that $\lambda_{K}^{E}$ is the shadow value placed on capital in East Germany and $\lambda_{K}^{W}$ is the shadow value placed on capital invested in Western Germany (or the rest of the world). Since there are only these two investment possibilities (investments in East Germany and investments outside East Germany) the following relation must hold $\lambda_{K}^{E}=-\lambda_{K}^{W}$. We now draw the following case distinction

1. Assume $\lambda_{K}^{E}<0$ (implying $\lambda_{K}^{W}>0$ ). Noting (15), (16), (17), and $\lambda_{K}^{E}=-\lambda_{K}^{W}$ this yields $\dot{K}=\dot{K}_{E}-\underbrace{\dot{K}_{W}}_{=0}=\gamma_{K} \lambda_{K}^{E}<0$.

2. Assume $\lambda_{K}^{E}=0$ (implying $\lambda_{K}^{W}=0$ ). Noting (15), (16), (17), and $\lambda_{K}^{E}=-\lambda_{K}^{W}$ this yields

$$
\dot{K}=\underbrace{\dot{K}_{E}}_{=0}-\underbrace{\dot{K}_{W}}_{=0}=0
$$

3. Assume $\lambda_{K}^{E}>0$ (implying $\lambda_{K}^{W}<0$ ). Noting (15), (16), (17), and $\lambda_{K}^{E}=-\lambda_{K}^{W}$ this yields $\dot{K}=\underbrace{\dot{K}_{E}}_{=0}-\dot{K}_{W}=-\gamma_{K} \lambda_{K}^{W}=\gamma_{K} \lambda_{K}^{E}>0$. 
In summary, the equation of motion for $K$ reads $^{15}$

$$
\dot{K}=\gamma_{K} \lambda_{K}^{E} \lesseqgtr 0 \text { for } \lambda_{K}^{E} \lesseqgtr 0
$$

As stated above, the focus is on Eastern Germany (or Eastern German regions). Therefore, we consider variables that relate to Eastern Germany only. Moreover, to simplify the notation we set $\lambda_{L}^{E}=\lambda_{L}$ and $\lambda_{K}^{E}=\lambda_{K}$. This notation then implies that expectations of Eastern German workers such that $\lambda_{L}<0$ implies pessimism in the sense that the difference between earnings in the domestic market sector and earnings in the outside option, in present value terms, is negative.

\subsection{Complete dynamic system and steady states}

From (11), (18), differentiating $\lambda_{L}(0)=\int_{0}^{\infty}[(1-\tau) w-\bar{w}] e^{-\rho t} d t$ with respect to $t$, and (13) the dynamic system which governs the evolution of the economy within the interior of the state space is as follows

$$
\begin{gathered}
\dot{L}=\gamma_{L} \lambda_{L} \\
\dot{K}=\gamma_{K} \lambda_{K} \\
\dot{\lambda}_{L}=\rho \lambda_{L}-[(1-\tau) w-\bar{w}] \\
\dot{\lambda}_{K}=\rho \lambda_{K}-[(1-\tau) r-\bar{r}] \\
L(0)=L_{0}, \quad K(0)=K_{0}
\end{gathered}
$$

where $w$ and $r$ are given by (4) and (5). Provided that $\lambda_{L}(0)$ and $\lambda_{K}(0)$ are specified, the above system describes a unique trajectory in four-dimensional $\left(L, K, \lambda_{L}, \lambda_{K}\right)$-space. However, $\lambda_{L}(0)$ and $\lambda_{K}(0)$ are not uniquely determined. There is rather an infinite number of shadow price combinations $\left\{\lambda_{L}(0), \lambda_{K}(0)\right\}$ which are admissible as self-fulfilling prophecies. It is nonetheless important to stress that any set of admissible expectations $\left\{\lambda_{L}(0), \lambda_{K}(0)\right\}$ is restricted to be

\footnotetext{
${ }^{15} \mathrm{We}$ assume that there is enough capital outside the economy for a simultaneous development of all regions heading towards the superior equilibrium.
} 
fundamentally warranted. That is, economic fundamentals and public policy restrict the range of admissible expectations, as explained in Section 4.1 below.

A steady state is determined by $\dot{L}=\dot{K}=\dot{\lambda}_{L}=\dot{\lambda}_{K}=0$. We first turn to the interior steady state. From $\dot{L}=\gamma_{L} \lambda_{L}$ and $\dot{K}=\gamma_{K} \lambda_{K}$ one recognizes that $\dot{L}=\dot{K}=0$ requires $\lambda_{L}=\lambda_{K}=0$. From (21), (22), $\lambda_{L}=\lambda_{K}=0$ (implying $\dot{\lambda}_{L}=\dot{\lambda}_{K}=0$ ) one gets $(1-\tau) w=\bar{w}$ and $(1-\tau) r=\bar{r}$. These two equations in $L$ and $K$ characterize the interior steady state in $(K, L)$-plane. ${ }^{16}$ Noting (4) and (5) and solving for $L$ gives

$$
\begin{gathered}
L=\left(\frac{\bar{r}}{(1-\tau) \alpha}\right)^{\frac{1-\beta}{1-\alpha}}(q \tau)^{\frac{-\beta}{1-\alpha}} K^{\frac{1-\alpha-\beta}{1-\alpha}} \\
L=\left(\frac{\bar{w}}{(1-\tau)(1-\alpha)}\right)^{\frac{1-\beta}{\beta-\alpha}}(q \tau)^{\frac{-\beta}{\beta-\alpha}} K^{\frac{\alpha}{\alpha-\beta}}
\end{gathered}
$$

Since $0<\frac{1-\alpha-\beta}{1-\alpha}<1$ the RHS of (23) is increasing and concave in $K$ and since $\frac{\alpha}{\alpha-\beta}>1$ (assuming $\alpha>\beta$ ) the RHS of (24) is increasing and convex in $K$. Hence, there is a unique interior solution $\left\{K^{*}, L^{*}\right\}$ (Figure 3, point A). There are also two boundary steady states. The lower (inferior) steady state is $\{K=0, L=0\}$ (Figure 3, point C). The upper (superior) steady state reads $\left\{K=K^{* *}, L=\bar{L}\right\}$ (Figure 3, point B).

As regards the dynamics at the border of the state space, two aspects need to be clarified. First, the economy remains at the boundary once it touches the border of the state space (see the appendix for details). Second, in a world of IRS we need to ensure that factor inflows sooner or later come to a halt. It is assumed that some political mechanism prevents more than a maximum amount of labor being supplied to the region's domestic market sector. This maximum amount of labor is denoted as $\bar{L}$. The maximum amount of capital, $K^{* *}$, is then endogenously determined by $(1-\tau) r\left(K^{* *}, \bar{L}\right)=\bar{r}$. To illustrate, assume that the economy hits, say, the upper $L$-boundary at $t=T$, i.e. $L(T)=\bar{L}$, with $0<K(T)<K^{* *}$. The dynamics of the economy is then governed by (20) and (22) (noting that $L(T)=\bar{L}$ ). The shadow price $\lambda_{K}$ at $t=T$ jumps in order to satisfy the

\footnotetext{
${ }^{16}$ Notice, however, that $(1-\tau) w=\bar{w}$ and $(1-\tau) r=\bar{r}$ are necessary but not sufficient for $\dot{L}=0$ and $\dot{K}=0$; sufficient for $\dot{L}=0(\dot{K}=0)$ is $\lambda_{L}=0\left(\lambda_{K}=0\right)$.
} 
transversality condition. Capitalists then increase the amount of capital allocated to the domestic market sector until $(1-\tau) r=\bar{r}$. This movement is sluggish because of convex adjustment costs (for details see the appendix).

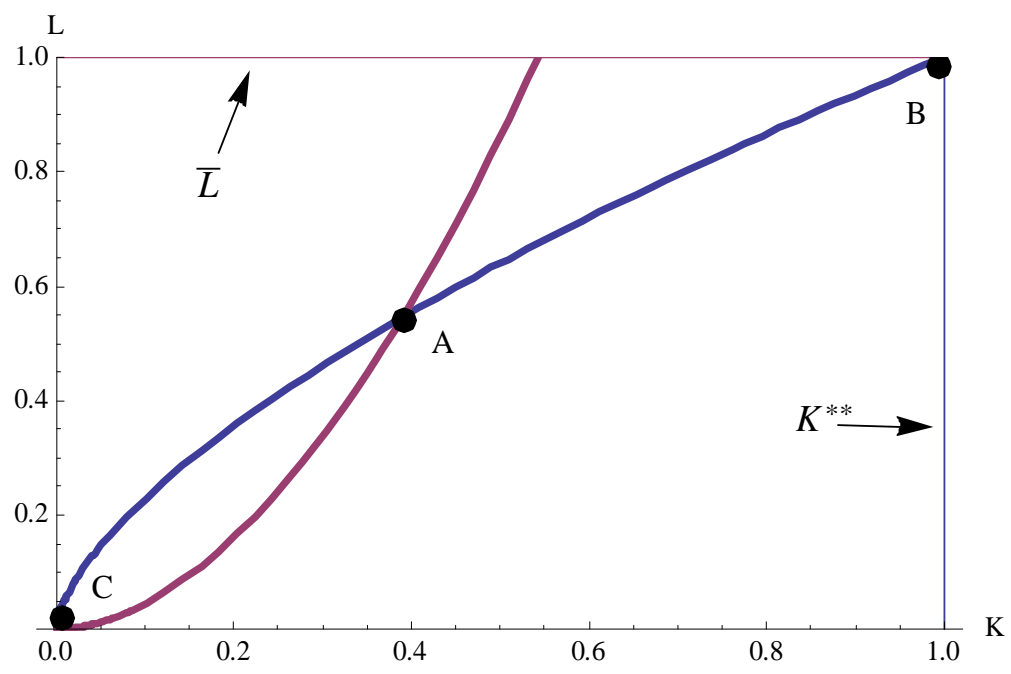

Figure 3: Multiple equilibria.

\section{Stability, equilibrium dynamics, and global indeterminacy}

The technical properties of the underlying model are discussed concisely in this section. This is a necessary prerequisite to understand the results outlined in Section 5 . We impose the parameter restriction $\alpha=\beta=0.5$. The dynamic system under study then becomes linear and allows for an analytical solution. This special case enables us to analyze the model more deeply and to demonstrate its implications. This procedure obviously comes at the cost of imposing an unrealistic parameter restriction since the implied degree of IRS is $2 .^{17}$ It must also be assumed that

\footnotetext{
${ }^{17}$ Schmitt-Grohé (1997) reviews the empirical evidence on IRS at the level of industries. She finds that the degree of IRS ranges from 1.03 to 1.4 (Schmitt-Grohé, 1997, Table 4; see also the literature cited in Graham and Temple, 2006). Moreover, empirical evidence indicates that $\beta \in[0.16,0.39]$ (Aschauer, 1989; Finn, 1993).
} 
some exogenous (political) mechanism prevents unlimited capital inflows; the maximum amount of capital is denoted as $\bar{K}$.

\subsection{Stability and equilibrium dynamics}

From $(1-\tau) w=\bar{w}$ and $(1-\tau) r=\bar{r}$ together with $w=0.5 q \tau K$ and $r=0.5 q \tau L($ from (4) and (5) together with $\alpha=\beta=0.5)$, the interior steady state turns out to read $L^{*}=\frac{2 \bar{r}}{(1-\tau) q \tau}, K^{*}=\frac{2 \bar{w}}{(1-\tau) q \tau}$, $\lambda_{L}^{*}=0$, and $\lambda_{K}^{*}=0$. It can be shown that there are always three eigenvalues with positive real parts (for details see the appendix). The interior steady state is hence unequivocally unstable. ${ }^{18}$ There is a three-dimensional unstable manifold leading away from the interior steady state. Since there are two (predetermined) state variables and two jump variables, there is indeterminacy in the sense of a multiplicity of admissible initial shadow prices $\left\{\lambda_{L}(0), \lambda_{K}(0)\right\}$ that constitute equilibrium dynamics. Figure 4 shows the (unstable) interior steady state (point A) and several possible equilibrium trajectories leading to one of the boundary steady states (point B or C). As regards the admissible equilibrium trajectories, several remarks are at order:

1. Equilibrium trajectories must approach the border of the state region tangential, i.e. satisfying either $\dot{L}(T)=\lambda_{L}(T)=0$ or $\dot{K}(T)=\lambda_{K}(T)=0$ ("soft landing condition"). Once the economy hits the border it does not return into the interior of the state space. Instead it moves along the boundary to one of the border equilibria (for details see the appendix).

2. Starting with initial conditions $L(0)=L_{0}$ and $K(0)=K_{0}$ there is an infinite number of shadow price combinations $\left\{\lambda_{L}(0), \lambda_{K}(0)\right\}$ which are admissible as self-fulfilling prophecies. Hence, there is an infinite number of equilibrium trajectories, indexed by initial shadow prices, satisfying the soft landing criterion.

3. Initial shadow prices are exogenous. The set of admissible shadow prices is, however, re-

\footnotetext{
${ }^{18}$ This proposition extends to the more general case where $\alpha=\beta=0.5$ does not hold. Figure A1 in the appendix demonstrates that the number of eigenvalues (at the interior steady state) with positive real parts does not change in response to (admissible) variations in $\alpha$ and $\beta$.
} 
stricted. More specifically, shadow prices must satisfy two conditions: (i) they must be fundamentally warranted, i.e. equal the present value of expected earning differentials and (ii) they must be compatible with equilibrium, i.e. induce a trajectory that satisfies the soft landing condition.

\subsection{Global indeterminacy (the "overlap")}

Both history (initial state variables) and expectations (initial shadow prices) determine to which equilibrium the region ultimately converges. If the region starts inside a specific $(K, L)$-set, expectations (initial shadow prices) determine whether the region moves towards the superior or inferior steady state, i.e. the model exhibits global indeterminacy. Within this "area of global indeterminacy" or "overlap", a term coined by Krugman (1991), knowledge about initial state variables is not sufficient to determine the final outcome. In contrast, if the economy starts with sufficiently unfavorable initial conditions (i.e. South-West of the overlap) it converges to the inferior steady state. Similarly, if it starts with sufficiently favorable initial conditions (i.e. North-East of the overlap) it converges to the superior steady state.

To visualize the overlap, we have discretized the state space, i.e. we have defined a grid of points in $(K, L)$-space. Then we have checked whether, for a specific $(K, L)$-combination, there is at least one set of admissible expectations $\left\{\lambda_{L}(0), \lambda_{K}(0)\right\}$ which gives rise to a trajectory leading to the superior steady state and, for the same $(K, L)$-combination, there is at least one set of admissible expectations $\left\{\lambda_{L}(0), \lambda_{K}(0)\right\}$ which gives rise to a trajectory leading to the inferior steady state. If this condition is satisfied, the $(K, L)$-combination under consideration is part of the overlap. If this is not the case, the specific $(K, L)$-combination lies outside the overlap. ${ }^{19}$

Figure 4 illustrates the basic logic of the model. The parameters $(\bar{K}, \bar{L})$ have been chosen such that the interior steady state is centered; in Figures 4 and $5 \bar{K}$ and $\bar{L}$ have been normalized to one. The overlap is represented by the shaded area. Consider a region starting at, say, point D.

\footnotetext{
${ }^{19}$ A description of the underlying numerical procedure is available from the authors upon request.
} 
Provided that agents are sufficiently optimistic (e.g., $\left.\lambda_{L}(0), \lambda_{K}(0)>0\right)$ both workers and capitalists increasingly engage in the region's domestic market sector. The economy moves towards the upper border $L=\bar{L}$. In contrast, if agents are pessimistic, i.e. $\lambda_{L}(0), \lambda_{K}(0)<0$, both labor and capital leave the region's domestic market sector and the economy is heading towards the lower $L$-border and eventually approaches the inferior equilibrium at point C. ${ }^{20}$

How can the boundary of the overlap intuitively be understood? To illustrate, consider a region with initial endowments such that this region is located inside the overlap close to the lower boundary (not displayed). There is both a set of pessimistic expectations that lead the economy to the inferior steady state and a set of optimistic expectations that lead the economy to the superior steady state. Now, think of a reduction of the initial amount of capital such that the new point is located outside (i.e. South-West of) the overlap. The situation has changed drastically in that there is now merely a set of pessimistic expectations that forces the economy to follow an unfavorable economic development. The economic reason can be seen by noting, first, that the, say, competitive wage rate decreases with the amount of capital allocated the domestic market sector, i.e. $w=0.5 q \tau K$, and, second, by noting that expectations are given by $\lambda_{L}(0)=\int_{0}^{\infty}[(1-\tau) w-\bar{w}] e^{-\rho t} d t$, implying that a reduction in $w$ decreases, ceteris paribus, $\lambda_{L}(0)$. Stated differently, successive reductions of capital sooner or later imply that expectations, which lead the economy to the superior steady state are not fundamentally warranted anymore. Hence, a sufficiently large reduction of capital moves the economy outside the overlap.

Figure 5 demonstrates the size of the overlap in response to changes of the share of local tax receipts used to finance productive government expenditures, $q$. Extensive experimentation has shown that the overlap increases with $q$. This makes good economic sense since an increase in $q$ strengthens the interdependence among the agents' decisions across groups. This becomes evident by recalling that the competitive wage rate is $w=0.5 q \tau K$ and the competitive interest rate reads

\footnotetext{
${ }^{20}$ Equilibrium trajectories could, of course, also hit the (lower or upper) $K$-boundary for interior $L$-values. This pattern is, however, rarely observed for plausible calibrations.
} 
$r=0.5 q \tau L$. Hence, a strict supply-side policy gives expectations a greater role.

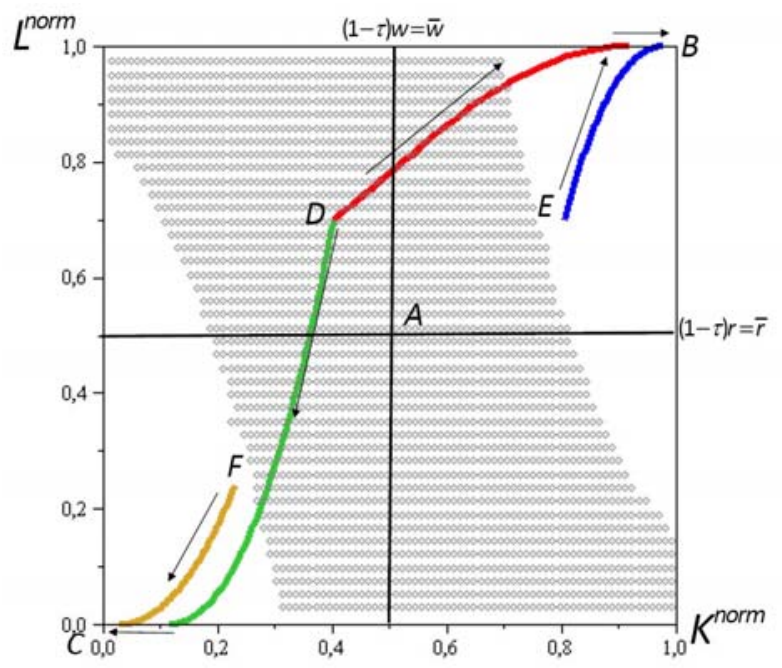

Figure 4: Three steady states and four possible equilibrium trajectories.

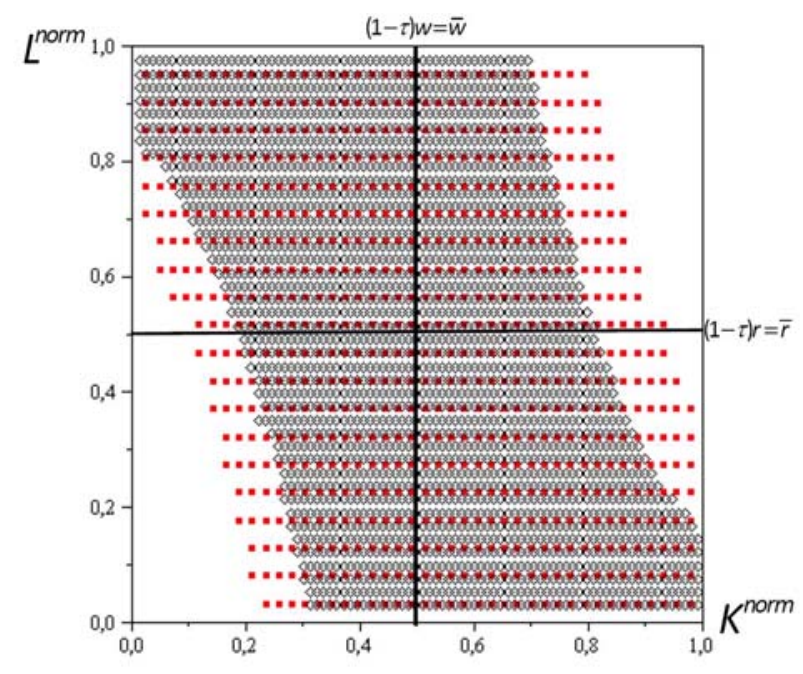

Figure 5: Overlap in response to $q$ (smaller, grey shaded area: $q=0.45$; larger, red shaded area:

$$
q=0.5)
$$

Is a large overlap good or bad? The answer is that it is neither good nor bad. A large overlap 
may imply that, even under unfavorable initial conditions, the economy is capable, due to strong optimism, of moving towards the superior steady state. In contrast, even under favorable initial conditions there is the risk that, due to a high degree of pessimism, the inferior steady state is ultimately realized. In this sense, the economy becomes more vulnerable against bad moods. Hence, an adequate, although fairly general, proposition states that the relative importance of expectations vis-à-vis history increases with the size of the overlap.

\section{Numerical evaluation}

\subsection{Sketch of the underlying procedure}

The model is evaluated in the following manner. First, we consider a "large number" of regions

$i \in\{1, \ldots, n\}$. Every region starts with a specific combination $\left\{K_{i}(0), L_{i}(0)\right\}$, which is restricted to fall inside the upper left of the state plane (see Figure 6 for an illustration). This assumption implies $(1-\tau) w_{i}<\bar{w}$ and $(1-\tau) r_{i}>\bar{r}$ being compatible with the empirical observations of (aggregate) labor outflows and (aggregate) capital inflows. Second, initial shadow prices $\lambda_{i, L}(0)$ are drawn from a normal distribution with given $E\left[\lambda_{i, L}(0)\right]$ and $V\left[\lambda_{i, L}(0)\right]$ (motivated below). The values of $\lambda_{i, K}(0)$ are then determined by the soft landing criterion, i.e. $\lambda_{i, L}(T)=0$ or $\lambda_{i, K}(T)=0$, where $T$ denotes the point in time when the economy hits a boundary. Once, $K_{i}(0), L_{i}(0), \lambda_{i, L}(0)$ and $\lambda_{i, K}(0)$ are specified, one can trace out $K_{i}(t), L_{i}(t)$ for all $t \in[0, T]$ and $i \in\{1, \ldots, n\}$. Third, we calculate the time path of average per capita income $y(t):=\frac{\sum Y_{i}(t)}{\sum L_{i}(t)}$. This is done for the baseline set of parameters. Finally, we change $E\left[\lambda_{i, L}(0)\right]$ to better understand the mechanics of the model. 


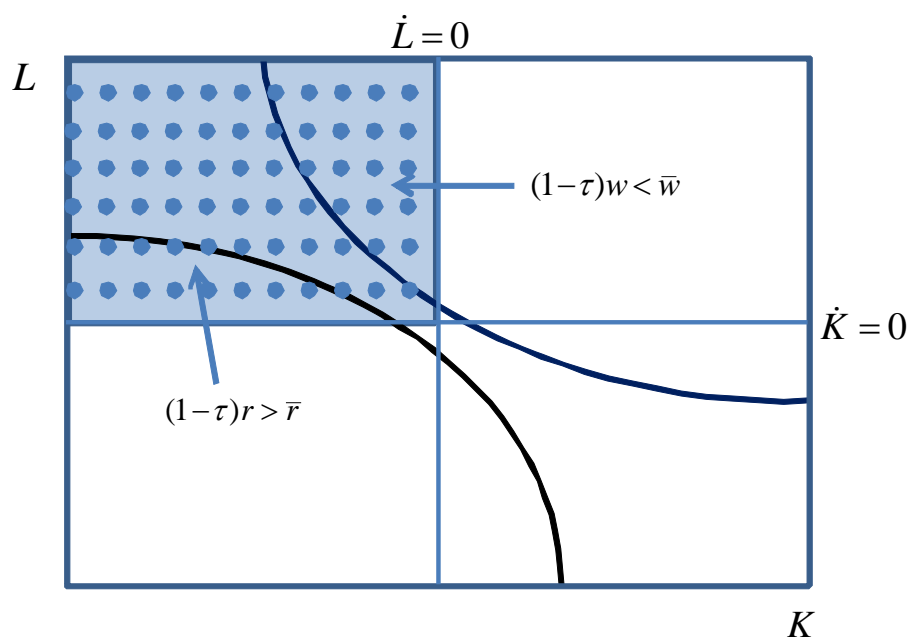

Figure 6: Illustration of the underlying procedure.

\subsection{Calibration}

Given $\alpha=\beta=0.5$ we aim at a careful specification of the remaining parameters. This procedure demonstrates that the model under study can be calibrated to a specific real-world economy. The baseline set of parameters is described by the following table.

Table 1: Baseline set of parameters.

\begin{tabular}{|l|c|}
\hline Technology and preferences & $\alpha=0.5 ; \beta=0.5 ; \gamma_{L}=\gamma_{K}=0.0042 ; \rho=0.02$ \\
\hline Policy and outside option & $\tau=0.36 ; q=0.45 ; \bar{r}=0.05 ; \bar{w}=1$ \\
\hline Initial moods & $E\left[\lambda_{L}(0)\right]=-11.11 ; V\left[\lambda_{L}(0)\right]=2$ \\
\hline
\end{tabular}

The time preference rate $\rho=0.02$ is in line with usual calibrations $(0.01 \leq \rho \leq 0.03)$. The tax rate $\tau=0.36$ is the average between the (marginal) capital income tax rate in 2000 (about 0.31 ) and the (marginal) labor income tax rate for the average earner in 2000 (about 0.4) (OECD, 2007). The policy parameter $q=0.45$ results from the following observation. The ratio of average public investment across all East German regional authorities (excluding Berlin) from 1992 to 2007 and average tax receipts across all Eastern German regional authorities (excluding Berlin) from 1992 
to 2007 amounts to $0.47 .^{21}$ The rate of return on capital (net of taxes) $\bar{r}$ is set to 5 percent and the wage rate in the outside option is normalized to one, i.e. $\bar{w}=1$.

We now turn to the determination of $E\left[\lambda_{L}(0)\right]$. Assume that the domestic market wage (net of taxes) converges to the wage rate given by the outside option $\bar{w}$ at a constant rate of 0.025 , i.e. ${ }^{22}$

$$
(1-\tau) w(t)-\bar{w}=[(1-\tau) w(0)-\bar{w}] e^{-0.025 t}
$$

Plugging the RHS into $\lambda_{L}(0)=\int_{0}^{\infty}[(1-\tau) w-\bar{w}] e^{-\rho t} d t$, using $\bar{w}=1$ such that $(1-\tau) w(1991)-$ $\bar{w} \simeq-0.5$ (Burda, 2006, Table 1), yields

$$
E\left[\lambda_{L}(0)\right]=\int_{0}^{\infty}[(1-\tau) w(0)-\bar{w}] e^{-0.025 t} e^{-0.02 t} d t=\frac{-0.5}{0.045} \cong-11.11
$$

The expected rate of wage convergence has a significant impact on economic confidence, parameterized by $E\left[\lambda_{L}(0)\right]$. We have assumed that the rate of wage convergence is 2.5 percent, which implies a half life of nearly 28 years. Alternatively, one can assume a rate of wage convergence of 6.5 percent, implying a half life of about 10 years (These numbers come closer to the scenario that was propagated at that time by German politicians who promised "blooming landscapes within 5 to 10 years"). In this case, the degree of pessimism would be $E\left[\lambda_{L}(0)\right]=\frac{-0.5}{0.085} \cong-5.9$.

The mobility cost parameter $\gamma_{L}$ is determined as follows. Notice at first that the size of the factor endowment box is chosen such that the interior steady state is centered along both the $K$-dimension and the $L$-dimension. Given the parameters we have specified so far this leads to $\left\{L^{*} \cong 0.96, K^{*} \cong 19.29\right\}$, i.e. $\left\{\bar{L}=2 L^{*}, \bar{K}=2 K^{*}\right\}$. In 1991 about 2.4 percent of the East German labor force left Eastern Germany. ${ }^{23}$ Now we can determine $\dot{L}$ in our model, which is $\hat{L}(91) * \bar{L}=-0.024 * 1.92\left(\hat{L}\right.$ denotes the growth rate). Noting $(11)$ the value for $\gamma_{L}$ is given by

$$
\gamma_{L}=\frac{\dot{L}}{\lambda_{L}}=\frac{-0.024 * 1.92}{-11.11} \cong 0.0042
$$

\footnotetext{
${ }^{21}$ Data on public investment are taken from Statistisches Bundesamt (2008a), data on tax receipts are taken from Statistisches Bundesamt (2008b).

${ }^{22}$ This procedure basically follows Burda (2006).

${ }^{23}$ See Burda (2006, p. 372) and the labor force data on www.statistik-bw.de/Arbeitskreis_VGR/tbls/tab16.asp.
} 
Capital mobility costs are set equal to labor mobility costs, i.e. $\gamma_{K}=\gamma_{L} \cdot{ }^{24}$ Finally, we set $V\left[\lambda_{L}(0)\right]=2$. Recall that $E\left[\lambda_{K}(0)\right]$ and $V\left[\lambda_{K}(0)\right]$ are endogenous.

\subsection{Dynamic implications}

Figure 7 shows the time path of average per capita income $y(t):=\frac{\sum Y_{i}(t)}{\sum L_{i}(t)}$ assuming either $E\left[\lambda_{i, L}(0)\right]=-11.11$ (Baseline Scenario) or $E\left[\lambda_{i, L}(0)\right]=-5.9$ (Scenario "Less Pessimism") for all $i \in\{1, \ldots, n\}$. The scenario "Less Pessimism" is compatible with an expected rate of wage convergence of 6.5 percent (instead of 2.5 percent in the Baseline Scenario). Average per capita income at $t=0$ has been normalized to one. Notice that per capita income at $t=0$ is the same for both scenarios since fundamentals are identical in both cases. The time paths clearly show that better economic confidence, i.e. a higher value of $E\left[\lambda_{i, L}(0)\right]$, ultimately leads to a higher level of per capita income.

The economic intuition for this observation is straightforward. Given the regional economic fundamentals $\left\{K_{i}(0), L_{i}(0)\right\}$ and public policy ( $\tau$ and $q$ ), comparably favorable moods induce more workers and capital owners to engage in the regions' domestic market sector. Consequently, the scenario "Less Pessimism" enables more regions to follow a favorable economic development heading towards the superior steady state compared to the Baseline Scenario. In the Baseline Scenario 42 percent of the regions converge to the superior steady state, while 58 percent are heading towards the inferior steady state state. In the scenario "Less Pessimism" 70 (30) percent converge to the superior (inferior) steady state. ${ }^{25}$

\footnotetext{
${ }^{24}$ One might object that capital is more mobile than labor, i.e. $\gamma_{K}>\gamma_{L}$. However, this is not clear if we think of real capital reallocation instead of reallocations of financial capital. Also, we have experimented with other constellations, i.e. $\gamma_{K}>\gamma_{L}$ and $\gamma_{K}<\gamma_{L}$. The qualitative results do not change.

${ }^{25}$ Regional per capita income may temporarily increase for regions which move towards the inferior steady state. This requires that labor leaves the region more rapidly than capital. Conversely, regional per capita income may decrease along the transition in regions moving towards the superior steady state.
} 


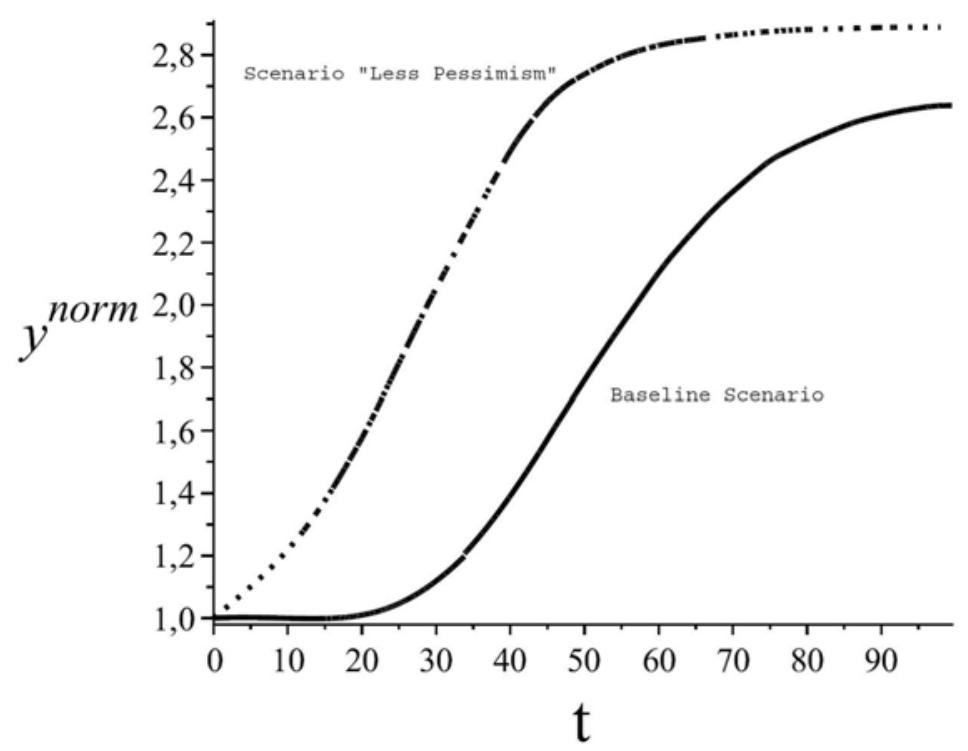

Figure 7: Time path of average per capita income under alternative moods.

The results of the comparative-dynamic exercises discussed above appear as gradual changes at the aggregate level. At the regional level, however, there may be drastic changes. An increase in economic confidence may imply that a specific region converges to the superior steady state instead of converging to the inferior steady state. Similarly, an increase in $q$ enlarges the overlap (see Figure 5 above). A specific region South-West of the initial overlap which gets included in the enlarged overlap is then capable of moving towards the superior steady state instead of being forced to follow an unfavorable development.

Finally, it should also be noticed that the associated structure of factor movements (not displayed) is in line with observed stylized facts listed above, i.e. there is aggregate labor outflow (stylized fact \#3), there is aggregate capital inflow (stylized fact \#4), and there is regional heterogeneity in labor movements. 


\section{Summary and conclusion}

Motivated by the process of economic development in Eastern Germany we have set up a dynamic macroeconomic model of a small open economy with factor mobility and aggregate increasing returns to scale. The model features multiple equilibria as well as (local and global) indeterminacy. Expectations matter for the resulting equilibrium dynamics implying that "economic confidence" may be crucial for economic development.

The employed analytical setup certainly ignores several aspects of the real world. It is hence even more remarkable that this simple model can replicate major stylized fact, like aggregate labor outflows (stylized fact \#3), and aggregate inflow of private capital (stylized fact \#4). It can therefore account for an asymmetric pattern of aggregate factor movements, as observed by Burda (2007). The model can also replicate regional heterogeneity in labor movements, as documented by stylized fact \#3 above. Moreover, the model can explain regional divergence of per capita incomes (stylized fact \#2). This result is in line with recent empirical findings. For instance, Vollmer et al. (2010, p. 10) investigate the convergence-divergence pattern among Eastern German regions and conclude "...that districts in the East converge to two different steady states regardless of their initial GDP". Taken together, the empirical observations and the results derived from the model set up above points to an economic structure and associated mechanisms that help to better understand some of the major stylized facts.

As regards the determinants of economic success of specific regions (or economies), the model does not provide a simple, but we think, an instructive story. The long term success of a specific region (or economy) results from the interaction between economic fundamentals, economic confidence, and public policy in a non-trivial fashion. More specifically, sufficiently favorable (unfavorable) initial conditions imply that a specific region experiences a favorable (unfavorable) economic development. For initial conditions in an intermediate range, expectations become crucial in the process of equilibrium selection. However, even though there is a multiplicity of admissible expectations it is important to notice that expectations must be fundamentally warranted. This implies 
that (admissible) expectations depend on initial conditions and on public policy. An intensification of, say, macroeconomic supply side policy (captured by an increase in the share of local tax receipts used to finance productive government expenditures, $q$ ) has two effects. First, it gives expectations a greater role by strengthening the interdependence among the agents' decisions to engage in the domestic market sector; technically speaking it increases the size of the overlap. Second, it allows agents to become more optimistic since the "degree of optimism" is measured by the difference between the Western German and the Eastern German wage rate, in present value terms, where the latter depends positively on $q$.

The model under study may also be helpful when it comes to better understand the "puzzle of limited convergence", as noted by Uhlig (2006). ${ }^{26}$ The numerical evaluation has demonstrated that the long run value of (average) per capita income depends critically on initial expectations. Moreover, the lower the expected rate at which the Eastern German converges to the Western German wage rate, the stronger is the implied degree of economic pessimism in Eastern Germany. Consequently, in a world with multiple equilibria and global indeterminacy, comparably many Eastern German regions experience an unfavorable economic development. In contrast, a higher expected rate of wage convergence implies a lower degree of pessimism such that more regions experience a favorable economic development. Therefore, the expected rate of wage convergence affects long run GDP per capita at the aggregate level.

\footnotetext{
${ }^{26}$ Real GDP per capita in Eastern relative to Western Germany stood at 30 percent in 1991, reached about 60 percent in 1996 and approached 70 percent in 2007 (Arbeitskreis "Volkswirtschaftliche Gesamtrechnungen der Laender", 2008(a)).
} 


\section{Appendix}

\subsection{Notes on stability $(\alpha=\beta=0.5)$}

We assume that $\alpha=\beta=0.5$. The Jacobian matrix of system (20) to (21) then reads as follows

$$
J=\left(\begin{array}{cccc}
0 & 0 & \gamma_{K} & 0 \\
0 & 0 & 0 & \gamma_{L} \\
0 & 0.5 q(1-\tau) \tau & \rho & 0 \\
0.5 q(1-\tau) \tau & 0 & 0 & \rho
\end{array}\right) .
$$

It can be readily shown that the eigenvalues of the Jacobian matrix are given by

$$
\begin{aligned}
& r_{1,2}=\frac{1}{2}\left[\rho \pm \sqrt{\rho^{2}-2 \sqrt{q^{2} \gamma_{L} \gamma_{K}(\tau-1)^{2} \tau^{2}}}\right], \\
& r_{3,4}=\frac{1}{2}\left[\rho \pm \sqrt{\rho^{2}+2 \sqrt{q^{2} \gamma_{L} \gamma_{K}(\tau-1)^{2} \tau^{2}}}\right] .
\end{aligned}
$$

Several remarks are at order:

1. Eigenvalues $r_{3,4}$ are always real-valued. Moreover, $r_{3}>0$ and $r_{4}<0$. This requires $\rho<$ $\sqrt{\rho^{2}+2 \sqrt{q^{2} \gamma_{L} \gamma_{K}(\tau-1)^{2} \tau^{2}}}$, which boils down to $q^{2} \gamma_{L} \gamma_{K}(\tau-1)^{2} \tau^{2}>0$ being always true.

2. As regards $r_{1,2}$, we need a case distinction: Provided that $\rho^{2}<2 \sqrt{q^{2} \gamma_{L} \gamma_{K}(\tau-1)^{2} \tau^{2}}$ eigenvalues $r_{1,2}$ are conjugate complex with positive real parts $\frac{1}{2} \rho>0$.

3. If, on the other hand, $\rho^{2}>2 \sqrt{q^{2} \gamma_{L} \gamma_{K}(\tau-1)^{2} \tau^{2}}$ eigenvalues $r_{1,2}$ are real valued. Eigenvalue $r_{1}>0$. Eigenvalue $r_{2}>0$ iff $\rho>\sqrt{\rho^{2}-2 \sqrt{q^{2} \gamma_{L} \gamma_{K}(\tau-1)^{2} \tau^{2}}}$. This condition boils down to $q^{2} \gamma_{L} \gamma_{K}(\tau-1)^{2} \tau^{2}>0$, which is always true.

The set of eigenvalues of the Jacobian matrix associated with the dynamic system (19), (20), (21), and (22) with $w$ and $r$ given by (4) and (5) exhibits the following pattern: there are three eigenvalues with positive real parts and one eigenvalue with negative real part. ${ }^{27}$ Since there are

\footnotetext{
${ }^{27}$ This can be shown analytically for $\alpha=\beta=0.5$. In addition, numerical evaluations indicate that this pattern is stable also in the non-linear case.
} 
two jump variables and three unstable roots, the interior steady state is unstable.

Local indeterminacy. There is a three-dimensional, unstable manifold which leads the economy away from the interior steady state. Since the state space has dimension two, there is (local) indeterminacy. Given an initial condition $K(0)=K_{0}$ and $L(0)=L_{0}$ there are different combinations $\left\{\lambda_{K}(0), \lambda_{L}(0)\right\}$ which lead the economy to the inferior steady state (superior steady state), i.e. there is a multiplicity of paths leading to the inferior steady state (superior steady state).

Global indeterminacy. Given an initial condition $K(0)=K_{0}$ and $L(0)=L_{0}$ inside the overlap there are different possible combinations $\left\{\lambda_{K}(0), \lambda_{L}(0)\right\}$ such that the economy evolves either to the inferior steady state $\{K=0, L=0\}$ or to the superior steady state $\left\{K=K^{* *}, L=\bar{L}\right\}$.

$$
\alpha=0.35
$$

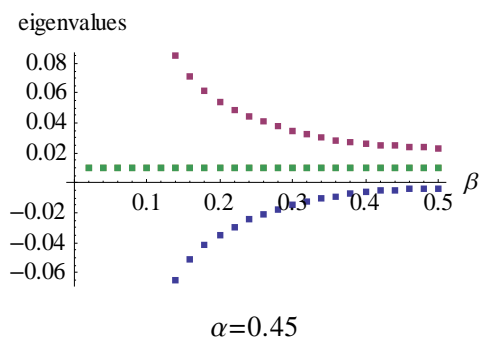

eigenvalues

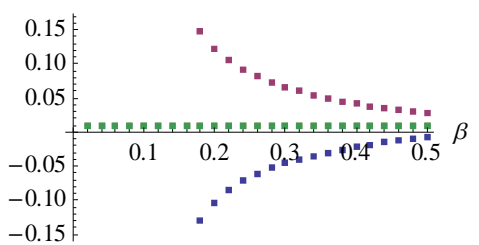

$\alpha=0.4$

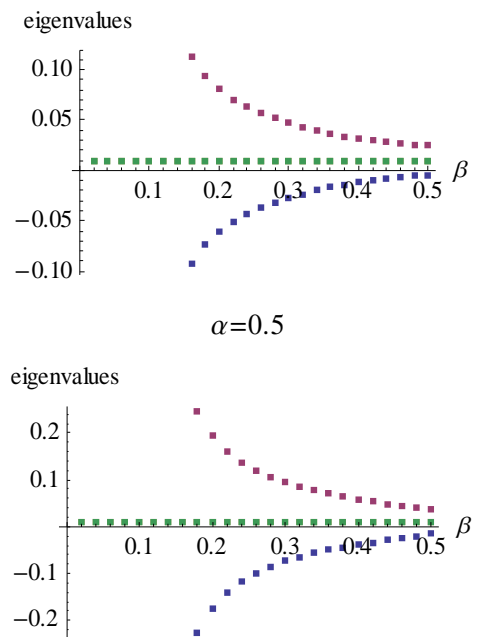

Figure A1: Eigenvalues (real parts) in response to changes in $\alpha$ and $\beta$. Notice that the horizontal line represents the two (identical) real parts of a pair of conjugate complex eigenvalues.

\subsection{Notes on equilibrium dynamics}

Reasoning of Fukao and Benabou (1993). Fukao and Benabou (1993, Proposition 2) have shown that, within the one-factor Krugman (1991) model, equilibrium trajectories must satisfy two conditions: (i) the shadow price of the factor reaching the boundary must approach zero and 
(ii) once the boundary has been touched, equilibrium implies that the economy remains at the boundary forever. The reasoning relies on an arbitrage condition, which must hold in equilibrium, and applies also to the model under study: assume that the economy hits, say, the lower $L$-boundary at $t=T$ (i.e. $L(T)=0$ with $K>0$ ) with $\lambda_{L}(T)<0$. In this case, each individual worker has an incentive to deviate from the trajectory under consideration since he can realize the gain, reflected by $\lambda_{L}(T)<0$, an instant in time later and thereby avoid all relocation costs (the individual is of measure zero) by moving one period later. Hence, any equilibrium trajectory must hit the $L$-boundary such that $\lambda_{L}(T)=0$.

A similar reasoning applies to the case when the economy is located at the boundary and remains there forever. Assume the economy is located at the lower $L$-boundary (i.e. $L=0$ and $K>0$ ). In this case $w>\bar{w}$ applies. It would indeed be optimal for workers to return into the domestic market sector. This will, however, never happen. Each individual worker has an incentive to realize the gain, reflected by $w>\bar{w}$, an instant in time later by moving alone and thereby avoiding relocation costs. Hence, the fact that the economy does not return into the interior of the state region is essentially due to a coordination failure in market equilibrium.

The arbitrage argument used here relies on one crucial assumption, namely that the individual agent is of measure zero. This guarantees that the deviation of any individual from a given trajectory does not change competitive factor rewards and hence leaves $\lambda_{K}$ and $\lambda_{L}$ unchanged. Moreover, this assumption guarantees that relocation costs are zero if one agent moves in isolation. ${ }^{28}$ Therefore, this reasoning extends to the two-factor case under consideration with atomistic agents implying that equilibrium trajectories must approach the border of the state region tangential, i.e. satisfying either $\dot{L}(T)=\lambda_{L}(T)=0$ or $\dot{K}(T)=\lambda_{K}(T)=0$ and, in addition, remains at the border of the state space once the economy hits the boundary.

Boundary dynamics. Assume that the economy hits, say, the $L$-border at $t=T$, i.e. $L(T)=$

\footnotetext{
${ }^{28}$ Notice that "reallocation costs" are essentially congestion costs, i.e. marginal moving costs are zero at the origin.
} 
0 or $L(T)=\bar{L}$, with $0<K(T)<\bar{K}$. The dynamics of the economy are then governed by $(20)$ and (22) (noting that $L(T)=0$ or $L(T)=\bar{L}$ ). The shadow price $\lambda_{K}$ at $t=T$ jumps in order to satisfy the transversality condition. Next assume that the economy hits the $K$-border at $t=T$, i.e. $K(T)=0$ or $K(T)=\bar{K}$, with $0<L(T)<\bar{L}$. The dynamics of the economy are then governed by (19) and (21) (noting that $K(T)=0$ or $K(T)=\bar{K}$ ). The shadow price $\lambda_{L}$ at $t=T$ jumps in order to satisfy the transversality condition. A non-formal sketch of equilibrium dynamics at the border of the state space is as follows. Assume that the economy touches the $K$-axis at $t=T$, i.e. $L(T)=0$. The rate of return then is $r(T)=0$ and, hence, capitalists leave the domestic market sector (in finite time). This movement is sluggish because of convex adjustment costs. An equivalent reasoning applies for $K(T)=0$ and $w(T)=0$. Now assume that the economy touches the upper border of the state region, i.e. $L(T)=\bar{L}$ for some $t=T$. Assume further that $(1-\tau) r(\bar{L}, \bar{K})>\bar{r}$. Capitalists then increase the amount of capital allocated to the domestic market sector until $(1-\tau) r=\bar{r}$. An equivalent reasoning holds true if the economy hits the right border of the state region $K=\bar{K}$.

\section{References}

[1] Arbeitskreis "Volkswirtschaftliche Gesamtrechnungen der Laender", Bruttoinlandsprodukt, Bruttowertschöpfung in den Laendern und Ost-West-Großraumregionen Deutschlands 1991 bis 2007, Reihe 1, Band 1, Stuttgart, 2008 (a) (www.vgrdl.de/Arbeitskreis_VGR).

[2] Arbeitskreis "Volkswirtschaftliche Gesamtrechnungen der Länder", Bruttoinlandsprodukt, Bruttowertschöpfung in den kreisfreien Staedten und Landkreisen Deutschlands 1992 und 1994 bis 2006, Reihe 2, Band 1, Stuttgart, 2008 (b) (www.vgrdl.de/Arbeitskreis_VGR).

[3] Aschauer, David A, Is Public Expenditure Productive? Journal of Monetary Economics, 1989, No 23, 177-200. 
[4] Barro, R.J., Government Spending in a Simple Model of Endogenous Growth, Journal of Political Economy, 1990, Vol. 98, No. 2, S103-S125.

[5] Barro, R. and X. Sala-i-Martin, Economic Growth, MIT Press, 2004.

[6] Benhabib, J. and R.E. Farmer, Indeterminacy and Increasing Returns, Journal of Economic Theory, 1994, 63, 19-41.

[7] Benhabib, Jess \& Farmer, Roger E.A., 1999. Indeterminacy and sunspots in macroeconomics, Handbook of Macroeconomics, in: J. B. Taylor \& M. Woodford (ed.), Handbook of Macroeconomics, Vol. 1, chapter 6, 387-448.

[8] Braun, J., Essays on Economic Growth and Migration, 1993, Cambridge MA, Harvard University, Ph.D. Dissertation.

[9] Bundesministerium für Verkehr, Bau und Stadtentwicklung, 2006, Jahresbericht der Bundesregierung zum Stand der Deutschen Einheit 2006, Berlin.

[10] Burda, Michael C., 2006. "Factor Reallocation in Eastern Germany after Reunification," American Economic Review, American Economic Association, vol. 96(2), pages 368-374, May.

[11] Burda, Michael, What kind of shock was it? Regional Integration and Structural Change in Germany after Unification, Kiel Working Paper No. 1306, January 2007.

[12] Deissenberg, C., G. Feichtinger, W. Semmler, and F. Wirl, History Dependence and Global Dynamics in Models with ME, Working Paper No. 12, Center for Empirical Macroeconomics, 2001.

[13] Finn, M. (1993). Is All Government Capital Produvtive? Federal Reserve Bank of Richmond, Economic Quarterly 79, 58-80.

[14] Fukao, F. and R. Benabou, History versus Expectations: A Comment, Quarterly Journal of Economics, 1993, 108, 535-542. 
[15] Funke, Michael \& Strulik, Holger, Growth and Convergence in a Two-Region Model of Unified Germany (with Michael Funke), German Economic Review, 2000, Vol. 1, 363-384.

[16] Graham, B.S. and J.R.W. Temple, Rich nations, poor nations: How much can multiple equilibria explain?, Journal of Economic Growth 11 (2006), 5-41.

[17] Hayashi, F., Tobin's Marginal q and Average q: A Neoclassical Interpretation, Econometrica, $1982,50,213-224$.

[18] Hunt, Jennifer, Staunching emigration from East Germany: age and the determinants of migration, Journal of the European Economic Society, 2006, 4(5), 1014-1037.

[19] Krugman, P., History versus Expectations, Quarterly Journal of Economics, 1991, 106, 651667.

[20] Murphy, K.M., A. Shleifer, R.W. Vishny, Industrialization and the Big Push, Journal of Political Economy, 1989, Vol. 97, No. 5, 1003-10026.

[21] OECD (2007), Tax Database,OECD, Paris, www.oecd.org/ctp/taxdatabase, Table I.1 and Table II.4.

[22] Schmitt-Grohé, S., Comparing Four Models of Aggregate Fluctuations due to Self-Fulfilling Expectations, Journal of Economic Theory, 1997, 72, 96-147

[23] Snower, Dennis J. \& Christian Merkl, 2006. "The Caring Hand that Cripples: The East German Labor Market after Reunification," American Economic Review, American Economic Association, vol. 96(2), pages 375-382, May

[24] Statistisches Bundesamt (2008), Genesis database (https://wwwgenesis.destatis.de/genesis/online/logon), GENESIS-Tabelle: 182-21-4, Wiesbaden.

[25] Statistisches Bundesamt (2008 a), Daten der Statistik über den Steuerhaushalt, Fachserie 14 Finanzen und Steuern, Reihe 2 Steuerhaushalt, Statistisches Bundesamt, Wiesbaden. 
[26] Statistisches Bundesamt (2008 b), Daten der Statistik über den Steuerhaushalt, Fachserie 14 Finanzen und Steuern, Reihe 4 Steuerhaushalt, Statistisches Bundesamt, Wiesbaden.

[27] Uhlig, Harald, 2006. "Regional Labor Markets, Network Externalities and Migration: The Case of German Reunification," American Economic Review, American Economic Association, vol. 96(2), pages 383-387, May.

[28] Vollmer, S., H. Holzmann, F. Ketterer, S. Klasen, Diverging Convergence in Unified Germany, Working Paper, 2010, University of Hannover. 


\section{CESifo Working Paper Series}

for full list see www.cesifo-group.org/wp

(address: Poschingerstr. 5, 81679 Munich, Germany, office@cesifo.de)

3120 Laszlo Goerke and Markus Pannenberg, 'Take it or Go to Court' - The Impact of Sec. 1a of the German Protection against Dismissal Act on Severance Payments -, July 2010

3121 Robert S. Chirinko and Daniel J. Wilson, Can Lower Tax Rates be Bought? Business Rent-Seeking and Tax Competition among U.S. States, July 2010

3122 Douglas Gollin and Christian Zimmermann, Global Climate Change and the Resurgence of Tropical Disease: An Economic Approach, July 2010

3123 Francesco Daveri and Maria Laura Parisi, Experience, Innovation and Productivity Empirical Evidence from Italy's Slowdown, July 2010

3124 Carlo V. Fiorio and Massimo Florio, A Fair Price for Energy? Ownership versus Market Opening in the EU15, July 2010

3125 Frederick van der Ploeg, Natural Resources: Curse or Blessing?, July 2010

3126 Kaisa Kotakorpi and Panu Poutvaara, Pay for Politicians and Candidate Selection: An Empirical Analysis, July 2010

3127 Jun-ichi Itaya, Makoto Okamura and Chikara Yamaguchi, Partial Tax Coordination in a Repeated Game Setting, July 2010

3128 Volker Meier and Helmut Rainer, On the Optimality of Joint Taxation for NonCooperative Couples, July 2010

3129 Ryan Oprea, Keith Henwood and Daniel Friedman, Separating the Hawks from the Doves: Evidence from Continuous Time Laboratory Games, July 2010

3130 Mari Rege and Ingeborg F. Solli, The Impact of Paternity Leave on Long-term Father Involvement, July 2010

3131 Olaf Posch, Risk Premia in General Equilibrium, July 2010

3132 John Komlos and Marek Brabec, The Trend of BMI Values by Centiles of US Adults, Birth Cohorts 1882-1986, July 2010

3133 Emin Karagözoğlu and Arno Riedl, Information, Uncertainty, and Subjective Entitlements in Bargaining, July 2010

3134 John Boyd, Gianni De Nicolò and Elena Loukoianova, Banking Crises and Crisis Dating: Theory and Evidence, July 2010

3135 Michael R. Baye, Dan Kovenock and Casper G. de Vries, The Herodotus Paradox, July 2010 
3136 Martin Kolmar and Hendrik Rommeswinkel, Group Contests with Complementarities in Efforts, July 2010

3137 Carolina Manzano and Xavier Vives, Public and Private Learning from Prices, Strategic Substitutability and Complementarity, and Equilibrium Multiplicity, July 2010

3138 Axel Löffler, Gunther Schnabl and Franziska Schobert, Inflation Targeting by Debtor Central Banks in Emerging Market Economies, July 2010

$3139 \mathrm{Yu}-\mathrm{Fu}$ Chen and Michael Funke, Global Warming and Extreme Events: Rethinking the Timing and Intensity of Environmental Policy, July 2010

3140 Lawrence M. Kahn, Labor Market Policy: A Comparative View on the Costs and Benefits of Labor Market Flexibility, July 2010

3141 Ben J. Heijdra, Jochen O. Mierau and Laurie S.M. Reijnders, The Tragedy of Annuitization, July 2010

3142 Erkki Koskela, Outsourcing Cost and Tax Progression under Nash Wage Bargaining with Flexible Outsourcing, July 2010

3143 Daniel Osberghaus and Christiane Reif, Total Costs and Budgetary Effects of Adaptation to Climate Change: An Assessment for the European Union, August 2010

3144 Philip E. Graves, Benefit-Cost Analysis of Environmental Projects: A Plethora of Systematic Biases, August 2010

3145 Sabrina Di Addario and Daniela Vuri, Entrepreneurship and Market Size. The Case of Young College Graduates in Italy, August 2010

3146 Shoshana Amyra Grossbard and Alfredo Marvăo Pereira, Will Women Save more than Men? A Theoretical Model of Savings and Marriage, August 2010

3147 Jarko Fidrmuc, Time-Varying Exchange Rate Basket in China from 2005 to 2009, August 2010

3148 Ilja Neustadt and Peter Zweifel, Is the Welfare State Sustainable? Experimental Evidence on Citizens' Preferences for Redistribution, August 2010

3149 Marcus Dittrich and Andreas Knabe, Wage and Employment Effects of Non-Binding Minimum Wages, August 2010

3150 Shutao Cao, Enchuan Shao and Pedro Silos, Fixed-Term and Permanent Employment Contracts: Theory and Evidence, August 2010

3151 Ludger Woessmann, Cross-Country Evidence on Teacher Performance Pay, August 2010

3152 Lorenzo C. G. Pozzi, Casper G. de Vries and Jorn Zenhorst, World Equity Premium Based Risk Aversion Estimates, August 2010 
3153 Volker Grossmann, Thomas M. Steger and Timo Trimborn, Dynamically Optimal R\&D Subsidization, August 2010

3154 Alexander Haupt, Tim Krieger and Thomas Lange, A Note on Brain Gain and Brain Drain: Permanent Migration and Education Policy, August 2010

3155 António Afonso and Christophe Rault, Long-run Determinants of Sovereign Yields, August 2010

3156 Franziska Tausch, Jan Potters and Arno Riedl, Preferences for Redistribution and Pensions. What can we Learn from Experiments?, August 2010

3157 Martin Kolmar and Andreas Wagener, Inefficient Group Organization as Optimal Adaption to Dominant Environments, August 2010

3158 Kai Carstensen, Klaus Wohlrabe and Christina Ziegler, Predictive Ability of Business Cycle Indicators under Test: A Case Study for the Euro Area Industrial Production, August 2010

3159 Horst Rottmann and Timo Wollmershäuser, A Micro Data Approach to the Identification of Credit Crunches, August 2010

3160 Philip E. Graves, Appropriate Fiscal Policy over the Business Cycle: Proper Stimulus Policies Can Work, August 2010

3161 Michael Binder and Marcel Bluhm, On the Conditional Effects of IMF Program Participation on Output Growth, August 2010

3162 Michael Binder, Qianying Chen, and Xuan Zhang, On the Effects of Monetary Policy Shocks on Exchange Rates, August 2010

3163 Felix J. Bierbrauer, On the Optimality of Optimal Income Taxation, August 2010

3164 Nikolaus Wolf, Europe's Great Depression - Coordination Failure after the First World War, September 2010

3165 Dan Kovenock and Brian Roberson, Conflicts with Multiple Battlefields, September 2010

3166 Jean-Pierre Ponssard and Catherine Thomas, Capacity Investment under Demand Uncertainty. An Empirical Study of the US Cement Industry, 1994-2006, September 2010

3167 Jørgen Juel Andersen, Jon H. Fiva and Gisle James Natvik, Voting when the Stakes are High, September 2010

3168 Michael Hoel, Is there a Green Paradox?, September 2010

3169 Scott Alan Carson, Nineteenth Century US African-American and White Female Statures: Insight from US Prison Records, September 2010 
3170 Gil S. Epstein, Yosef Mealem and Shmuel Nitzan, Political Culture and Discrimination in Contests, September 2010

3171 Sara Fisher Ellison, Jeffrey Greenbaum and Wallace P. Mullin, Diversity, Social Goods Provision, and Performance in the Firm, September 2010

3172 Silvia Dominguez-Martinez, Randolph Sloof and Ferdinand von Siemens, Monitoring your Friends, not your Foes: Strategic Ignorance and the Delegation of Real Authority, September 2010

3173 Marcus Dittrich and Beate Schirwitz, Union Membership and Employment Dynamics: A Note, September 2010

3174 Francesco Daveri, Paolo Manasse and Danila Serra, The Twin Effects of Globalization - Evidence from a Sample of Indian Manufacturing Firms, September 2010

3175 Florian Blöchl, Fabian J. Theis, Fernando Vega-Redondo and Eric O’N. Fisher, Which Sectors of a Modern Economy are most Central?, September 2010

3176 Dag Morten Dalen, Marilena Locatelli and Steinar Strøm, Longitudinal Analysis of Generic Substitution, September 2010

3177 Armin Falk, Stephan Meier and Christian Zehnder, Did we Overestimate the Role of Social Preferences? The Case of Self-Selected Student Samples, September 2010

3178 Christian Fahrholz and Cezary Wójcik, The Bail-Out! Positive Political Economics of Greek-type Crises in the EMU, September 2010

3179 Klaus Abberger and Wolfgang Nierhaus, The Ifo Business Cycle Clock: Circular Correlation with the Real GDP, September 2010

3180 Walter Krämer and Gerhard Arminger, "True Believers" or Numerical Terrorism at the Nuclear Power Plant, September 2010

3181 Bernard M.S. Van Praag, Dmitri Romanov and Ada Ferrer-i-Carbonell, Happiness and Financial Satisfaction in Israel. Effects of Religiosity, Ethnicity, and War, September 2010

3182 Dimitrios Koumparoulis and Paul De Grauwe, Public Capital, Employment and Productivity: An Empirical Investigation for Greece, September 2010

3183 John Whalley and Tanmaya Shekhar, The Rapidly Deepening India-China Economic Relationship, September 2010

3184 Andreas Schäfer and Thomas Steger, History, Expectations, and Public Policy: Economic Development in Eastern Germany, September 2010 